\title{
Microstructural Subsequence and Phase Equilibria in an Age-Hardenable Cu-Ni-Si Alloy
}

\author{
Satoshi Semboshi ${ }^{1, *}$, Mikio Ishikuro ${ }^{1}$, Akihiro Iwase ${ }^{2}$ and Takayuki Takasugi ${ }^{2}$ \\ ${ }^{1}$ Institute for Materials Research, Tohoku University, Sendai 980-8577, Japan \\ ${ }^{2}$ Department of Materials Science, Osaka Prefecture University, Sakai 599-8531, Japan
}

\begin{abstract}
We investigated the microstructural subsequence and phase equilibrium of $\mathrm{Cu}-4.3$ at $\% \mathrm{Ni}-2.2$ at $\% \mathrm{Si}$ alloy specimens during isothermal aging over a temperature range of $698 \mathrm{~K}$ to $873 \mathrm{~K}$. During aging in this temperature range, the microstructure of the specimens evolved in the following sequence; continuous precipitation of fine disk-shaped $\delta$ - $\mathrm{Ni}_{2} \mathrm{Si}$ in the matrix, discontinuous precipitation of cellular components containing coarse fiber-shaped $\delta-\mathrm{Ni}_{2} \mathrm{Si}$ at grain boundaries, and then occupation of the specimen with cellular components. By analyzing the variations in the hardness and electrical conductivity with aging time as well as temperature, we described the kinetics of the highest number density of fine $\delta-\mathrm{Ni}_{2} \mathrm{Si}$ continuous precipitates. Based on the chemical analyses of the specimen in a phase equilibrium state using an extraction procedure, we proposed a revised solvus of solutes $\mathrm{Ni}$ and $\mathrm{Si}$ in the $\mathrm{Cu}$ solid solution phase, as well as $\mathrm{Cu}$ in the $\delta$ - $\mathrm{Ni}_{2} \mathrm{Si}$ intermetallic phase in a $\mathrm{Cu}-\delta-\mathrm{Ni}_{2} \mathrm{Si}$ pseudo-binary system. [doi:10.2320/matertrans.MC201706]
\end{abstract}

(Received May 30, 2017; Accepted September 19, 2017; Published October 20, 2017)

Keywords: copper alloy, precipitates, phase equilibrium, solvus, chemical extraction, ICP-OES

\section{Introduction}

Among various $\mathrm{Cu}$-based systems, age-hardenable $\mathrm{Cu}$ $\mathrm{Ni}$-Si Corson-type alloys are widely used for electrical connectors and lead frames because of their superior balance of strength and electrical conductivity. Alloys with a typical composition of less than 5 at\% $\mathrm{Ni}$ and 2.5 at\% $\mathrm{Si}$ at an $\mathrm{Ni} / \mathrm{Si}$ ratio of around 2.0 have been commercially fabricated by solid-solutioning at around $1173 \mathrm{~K}$ followed by aging over a temperature range of $673 \mathrm{~K}-773 \mathrm{~K}$. Optimal thermomechanical processing in combination with working and aging can produce tensile strengths of more than $1000 \mathrm{MPa}$ and an electrical conductivity in excess of $30 \%$ IACS. Here, "\% IACS" represents the percentage based on the conductivity defined in the International Annealed Copper Standard at $298 \mathrm{~K}$, that is, $5.8 \times 10^{7} \Omega^{-1} \mathrm{~m}^{-1}$. The balance of their hardness and electrical conductivity is competitive with that of the widely used $\mathrm{Cu}$-Be based alloys ${ }^{1,2)}$. Therefore, a number of fundamental and practical research efforts addressing $\mathrm{Cu}$ $\mathrm{Ni}$-Si alloys have been attempted to understand the mechanisms affecting age-induced microstructural evolution and to further improve their superior properties ${ }^{3-9}$ ).

It is generally recognized that the strengths and electrical conductivities of $\mathrm{Cu}-\mathrm{Ni}-\mathrm{Si}$ alloys are closely dependent on their microstructure; at an early stage of aging, the strength of the alloys increases owing to the continuous nucleation and growth of the nano-scaled $\delta-\mathrm{Ni}_{2} \mathrm{Si}$ precipitates (i.e., continuous precipitates (CPs)) in the matrix of $\mathrm{Cu}$ solid-solution phase ${ }^{10-17)}$. Here, $\delta-\mathrm{Ni}_{2} \mathrm{Si}$ has an orthorhombic structure (Space group: Pnma, lattice parameter: $a=0.504 \mathrm{~nm}, b=$ $0.364 \mathrm{~nm}, c=0.708 \mathrm{~nm})^{14,17,18)}$. At a later stage of a prolonged aging, the strength decreases, which is primarily caused by the development of coarse cellular components consisting of the $\mathrm{Cu}$ solid-solution and fiber-shaped $\delta-\mathrm{Ni}_{2} \mathrm{Ni}$ phase (i.e., discontinuous precipitates (DPs)), accompanied by the consumption of the fine $\delta-\mathrm{Ni}_{2} \mathrm{Ni}$ hardening species $^{17,19-21)}$. Meanwhile, the electrical conductivity of the al-

*Corresponding author, E-mail: semboshi@imr.tohoku.ac.jp loys increases monotonically during aging, because the amount of solute $\mathrm{Ni}$ and $\mathrm{Si}$ elements in the matrix decreases as a result of the formation of fine CPs and fiber DPs of $\delta-\mathrm{Ni}_{2} \mathrm{Si}$. Thus, to control the mechanical and electrical properties of the alloys, it is important to understand the precipitation behavior in association with the microstructures. The purpose of the present study is, therefore, to investigate the microstructural subsequence and phase equilibrium of commercial $\mathrm{Cu}-4.3$ at\% Ni-2.2 at\% $\mathrm{Si}$ alloy during isothermal aging over a wide temperature range of $698 \mathrm{~K}-873 \mathrm{~K}$. As a particular feature of this study, a chemical extraction technique was used to quantitatively analyze the microstructure of the aged-specimens ${ }^{17,22,23)}$. The adopted chemical extraction procedure allowed direct and reliable examination of the structure, volume fraction, and compositions of the constituent phases. Based on the obtained results, the kinetics and phase equilibrium of the aged microstructure are discussed.

\section{Experimental}

Alloy blocks measuring $30 \mathrm{~mm} \times 30 \mathrm{~mm} \times 3 \mathrm{~mm}$ were used as the starting material. The chemical composition of the alloys was $\mathrm{Cu}-4.3 \mathrm{Ni}-2.2 \mathrm{Si}$ in at\% $(\mathrm{Cu}-4.1 \mathrm{Ni}-1.0 \mathrm{Si}$ in mass $\%$ ). The blocks were cold-rolled down to a thickness of $0.3 \mathrm{~mm}$, and then cut off into strips measuring $75 \mathrm{~mm} \times$ $5 \mathrm{~mm} \times 0.3 \mathrm{~mm}$. The specimens were solution-treated at $1173 \mathrm{~K}$ for $3 \mathrm{~h}$ in evacuated quartz capsules, and then immediately quenched in water. The contaminated surface layer on the specimens was removed by mechanical polishing. The specimens were re-capsuled in a vacuum of less than $1.0 \times 10^{-2} \mathrm{~Pa}$, followed by isothermal aging at $698 \mathrm{~K}$, $723 \mathrm{~K}, 773 \mathrm{~K}$, and $873 \mathrm{~K}$ for $0.083 \mathrm{~h}-530 \mathrm{~h}$.

The microstructure of the specimens was observed using a JEOL JSM7001F field emission- scanning electron microscope (FESEM). For the FESEM observations, the specimens were first mechanically polished and then electrochemically polished with a $40 \%$ phosphoric acid water solution at room temperature for 5 to $10 \mathrm{~s}$. The Vickers hard- 
ness and electrical conductivity at room temperature were measured to monitor the microstructural evolution of the specimens during isothermal aging. The Vickers hardness tests were performed using a MITSUTOYO HM101 Vickers micro-hardness tester with an applied load of $1.96 \mathrm{~N}$, and the hardness values were then determined by averaging the values from more than 10 indentations. The electrical resistance of the specimens was measured using a standard DC four-probe method with an Agilent 34420A micro-ohm meter with an accuracy of $\pm 10 \mu \Omega$, which was then used to calculate the electrical conductivity. The precipitates formed in the aged specimens were separated using the following extraction procedure, the details of which are described in the literature ${ }^{17,22)}$ : the surfaces of the aged specimens were mechanically polished again to remove the contaminated surface layer. After the specimens had been thoroughly rinsed in pure ethanol, they were cut into small pieces. These pieces were immersed in a 7-mol/L nitric acid/water solution at $273 \mathrm{~K}$ for $0.3 \mathrm{~h}$. As a result, the $\mathrm{Cu}$ matrix phase dissolved in the solution, but the $\mathrm{Ni}$ and Si-rich precipitate phase remained as insoluble residue. The solution was then passed through a membrane filter with a pore diameter of $50 \mathrm{~nm}$. The filtered precipitates were rinsed well with pure water and then dried in a desiccator. The structure of the separated precipitates was analyzed by X-ray diffraction (XRD) using a PANalytical X'pert Pro diffractometer with $\mathrm{CuK} \alpha$ radiation (wave length, $\lambda=0.1542 \mathrm{~nm}$ ) and an applied voltage of $40 \mathrm{kV}$. The weight fractions of the elemental
$\mathrm{Cu}, \mathrm{Ni}$, and $\mathrm{Si}$ in the precipitates and matrix were obtained by measuring those in the filtered residue and filtrate, respectively, by inductively coupled plasma-optical emission spectrometry (ICP-OES) using a Thermo Fisher Scientific IRIS Advantage DUO spectrometer. Here, the filtered residue, which was identified as being $\delta$ - $\mathrm{Ni}_{2} \mathrm{Si}$, described latter, was dissolved in a solution of nitric acid, hydrofluoric acid, and pure water (at a ratio of $2: 1: 4$ ) at $373 \mathrm{~K}$ for $1 \mathrm{~h}$ in a closed Teflon container, before the ICP-OES measurements ${ }^{17)}$.

\section{Results and Discussion}

\subsection{Microstructural subsequence}

The solution-treated and quenched $\mathrm{Cu}-4.3 \mathrm{Ni}-2.2 \mathrm{Si}$ (in at $\%$ ) alloy specimen exhibited a single-phase microstructure of a supersaturated $\mathrm{Cu}$ solid solution with an average grain size of approximately $100 \mu \mathrm{m}$. Figure 1 shows FESEM micrographs of the specimen aged at $723 \mathrm{~K}$. In an early stage of aging for $4 \mathrm{~h}$ shown in Fig. 1(a), we can find areas of weak contrast with a size of several nanometers in the solid solution phase (see the right-hand side of the inset image, observed at a high magnification), which must correspond to continuous precipitates (CPs) of $\delta-\mathrm{Ni}_{2} \mathrm{Si}^{17)}$. We can also find some areas of bright contrast as indicated by the dotted circles in Fig. 1(a), which corresponds to the fiber-shaped discontinuous precipitates (DPs) of $\delta-\mathrm{Ni}_{2} \mathrm{Si}$ with the same orthorhombic structure as the CPs, which is confirmed in a
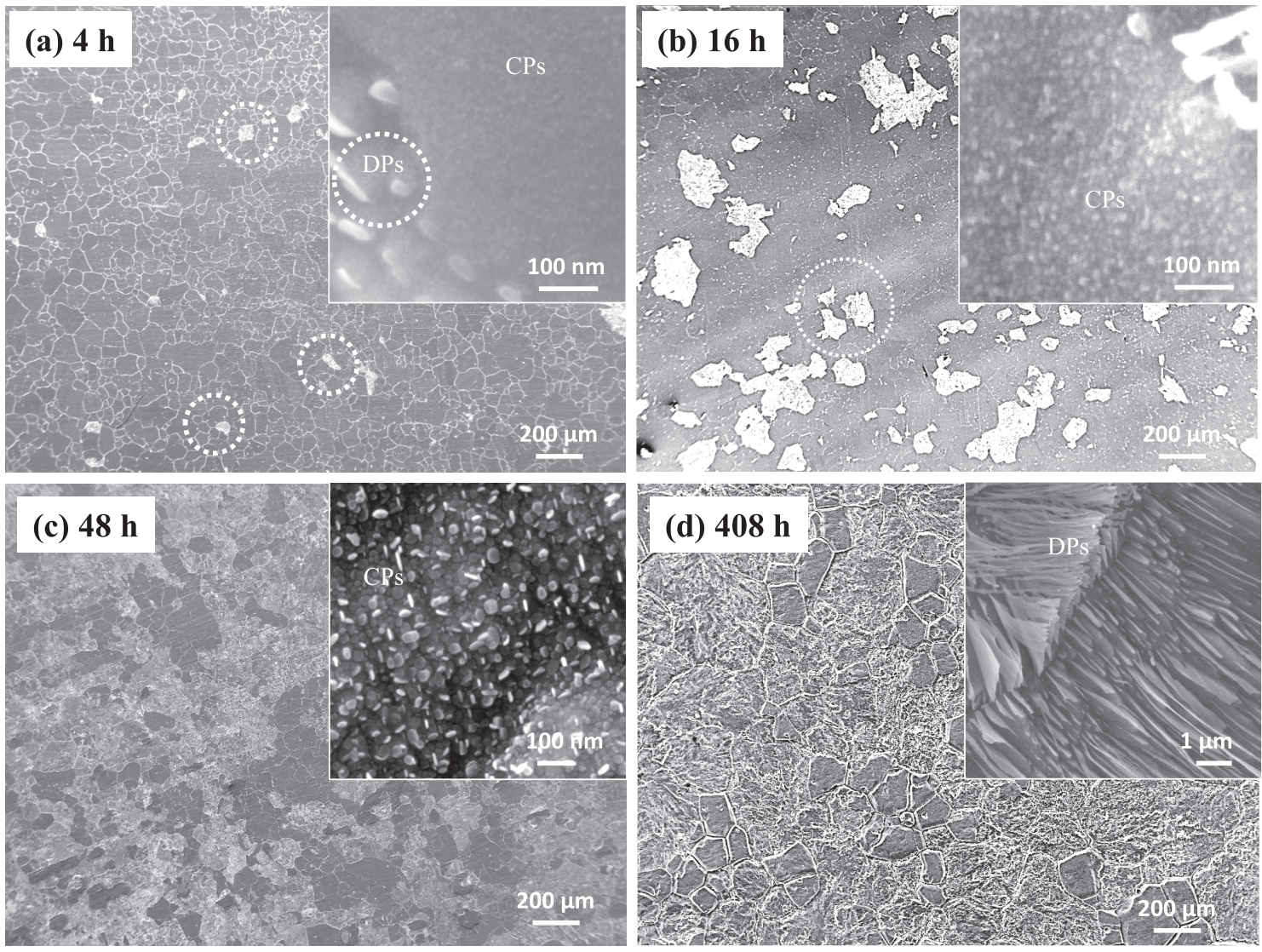

Fig. 1 FESEM micrographs for Cu-4.3 at\% Ni- 2.2 at $\%$ Si alloy specimen aged at $723 \mathrm{~K}$ for (a) $4 \mathrm{~h}$, (b) $16 \mathrm{~h}$, (c) $48 \mathrm{~h}$ and (d) $408 \mathrm{~h}$. In the magnified FESEM micrograph insets (a)-(c), fine continuous precipitates (CPs) appear in the grain. The dotted open circles in (a) and (b) indicate the region of the cellular components containing the fiber-shaped discontinuous precipitates (DPs). 
later section. Thus, the fiber-shaped DPs have already been formed at an early stage of aging, together with the formation of fine CPs. During prolonged aging, the fine CPs continuously nucleated and homogeneously dispersed in the matrix of the $\mathrm{Cu}$ solid solution, and then grew into diskshaped particles with a size of several tens of nanometers, as seen in the inset micrographs of Figs. 1(b)-(c). The cellular components composed of the fiber DPs and $\mathrm{Cu}$ solid solution phase developed spontaneously, consuming the sound grains containing the fine CPs. Finally, the cellular components occupied almost the entire region of the specimen, as shown in Fig. 1(d). No apparent microstructural evolution could be observed for a prolonged aging period longer than $408 \mathrm{~h}$.

A similar microstructural result, i.e., continuous precipitation of fine disk-shaped $\delta-\mathrm{Ni}_{2} \mathrm{Si}$ particles, discontinuous precipitation of cellular components containing coarse fiber-shaped $\delta-\mathrm{Ni}_{2} \mathrm{Si}$, and the eventual occupation of the specimen with cellular components, was observed for the specimens aged at every temperature between $698 \mathrm{~K}-873 \mathrm{~K}$. This indicates that, in the investigated temperature range, the equilibrium state for the alloy with a composition of $\mathrm{Cu}$ 4.3 at\% Ni- 2.2 at\% Si consists of two phases, namely, the $\mathrm{Cu}$ solid solution and the $\delta-\mathrm{Ni}_{2} \mathrm{Si}$ formed both continuously and discontinuously.

To investigate the kinetics of the microstructural subsequence during aging, we examined the variations in the Vickers hardness and electrical conductivity for the specimens aged at temperatures of $698 \mathrm{~K}, 723 \mathrm{~K}, 773 \mathrm{~K}$, and $873 \mathrm{~K}$ as a function of the aging time, as shown in Fig. 2. The Vickers hardness of the quenched specimens was $87 \pm$ $5 \mathrm{HV}$. During aging at the investigated temperatures, the hardness increased and then reached a maximum, after which it decreased at a rate, as shown in Fig. 2 (a). The maximum values of the hardness decreased with the aging tem-

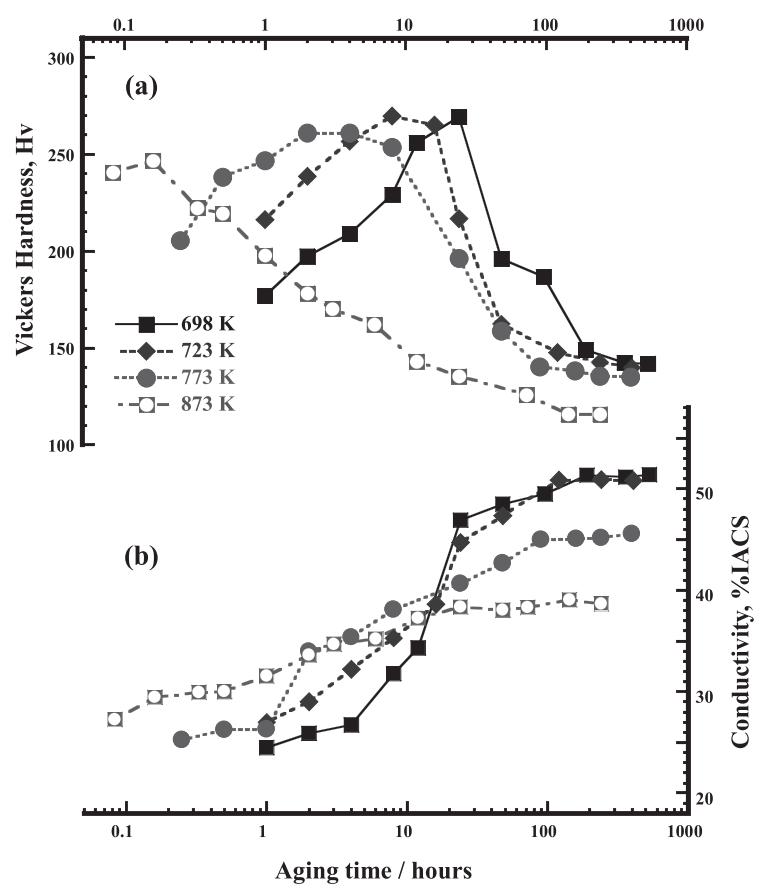

Fig. 2 (a) Vickers hardness and (b) electrical conductivity for $\mathrm{Cu}-4.3$ at\% Ni- 2.2 at\% Si alloy specimens aged between $698 \mathrm{~K}-873 \mathrm{~K}$. perature, although the period required to achieve the maximum hardness was reduced. The electrical conductivity of the quenched specimens was $14.5 \%$ IACS. The electrical conductivity of the specimen increased with the aging time and then reached saturation at every temperature (Fig. 2(b)). The saturated values of the conductivity decreased as the aging temperature increased, although the period required to reach saturation was shortened.

The hardness of the age-hardened specimen should be affected mainly by structural factors, such as the size and number density of the precipitates, together with the composition and volume fraction of the constituent phases. It is also accepted that the electrical conductivity (and resistivity) of the metallic materials are sensitive to the composition and volume fraction of the constituent phases ${ }^{24,25)}$. Therefore, the saturation of both the hardness and electrical conductivity indicates that the specimens should be virtually in an equilibrium state, at least in terms of microstructural subsequence. Thus, the time required to reach the equilibrium state was roughly obtained, from Fig. 2, as $360 \mathrm{~h}$ for the specimen aged at $698 \mathrm{~K}, 240 \mathrm{~h}$ for that aged at $723 \mathrm{~K}, 168 \mathrm{~h}$ for that aged at $773 \mathrm{~K}$, and $144 \mathrm{~h}$ for that aged at $873 \mathrm{~K}$.

Figure 3 shows the Arrhenius plots describing the saturation of both the hardness and electrical conductivity during isothermal aging, together with the maximum-hardening condition. The data points are well plotted on a straight line in the temperature range between $698 \mathrm{~K}-873 \mathrm{~K}$, which were fitted using the following equation:

$$
\begin{gathered}
\text { Condition of maximum-hardening: } \\
\ln (t)=-20.9+16.8 \times 10^{3} / T
\end{gathered}
$$

Saturation of electrical conductivity:

$$
\ln (t)=1.47+2.96 \times 10^{3} / T
$$

where $t$ is the aging time $[\mathrm{h}]$ and $T$ is the aging temperature $[\mathrm{K}]$. Equations (1) and (2) approximately correspond to the

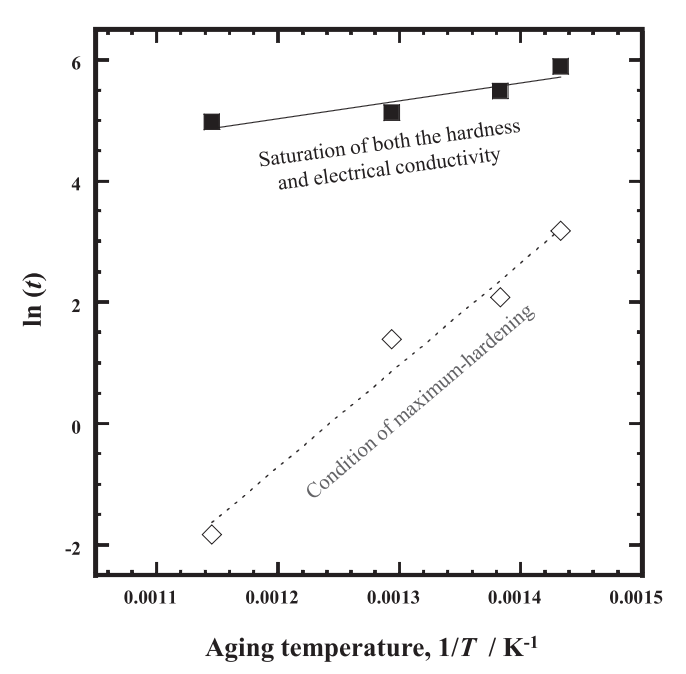

Fig. 3 Arrhenius plots of the aging temperature, $1 / T$, versus aging time in hours (represented by $\ln (t)$ ), which describe the saturation of both the hardness and electrical conductivity (indicated by $\square$ ) and the peak-hardened condition (indicated by $\diamond$ ) for $\mathrm{Cu}-4.3$ at $\% \mathrm{Ni}-2.2$ at $\% \mathrm{Si}$ alloy specimens. The former corresponds to the condition in which the equilibrium state is reached, while the latter corresponds to the fine continuous precipitates of $\delta-\mathrm{Ni}_{2} \mathrm{Si}$. 
kinetics required to reach the highest density of $\mathrm{CP} \delta-\mathrm{Ni}_{2} \mathrm{Si}$ and the phase equilibrium, respectively.

\subsection{Phase equilibrium}

We assumed that the specimen aged beyond the period given by eq. (2) should be in an equilibrium state. To confirm the structure of the precipitates in the equilibrium state, the precipitates of the fully aged specimens were separated by the extraction procedure, and were then subjected to XRD analysis. Figure 4 shows the appearance of the precipitates separated from the specimen aged at $723 \mathrm{~K}$ for $408 \mathrm{~h}$. We can see fibers measuring several tens of $\mathrm{nm}$ in diameter and several $\mu \mathrm{m}$ in length, and a small number of fine particles with a size of several tens of $\mathrm{nm}$. This morphological feature is consistent with the DPs and CPs, respectively, shown in Fig. 1(d). Figure 5 shows the XRD profile of the precipitates separated from the specimen, which exhibited peaks corresponding to $\delta$ - $\mathrm{Ni}_{2} \mathrm{Si}$ with an orthorhombic structure having a space group of Pnma. Therefore, the precipitates in the aged specimens were identified as $\delta$ - $\mathrm{Ni}_{2} \mathrm{Si}$.

The compositions and volume fractions of the constituent matrix and precipitates for the aged specimens can be also evaluated directly by performing ICP-OES analyses on the

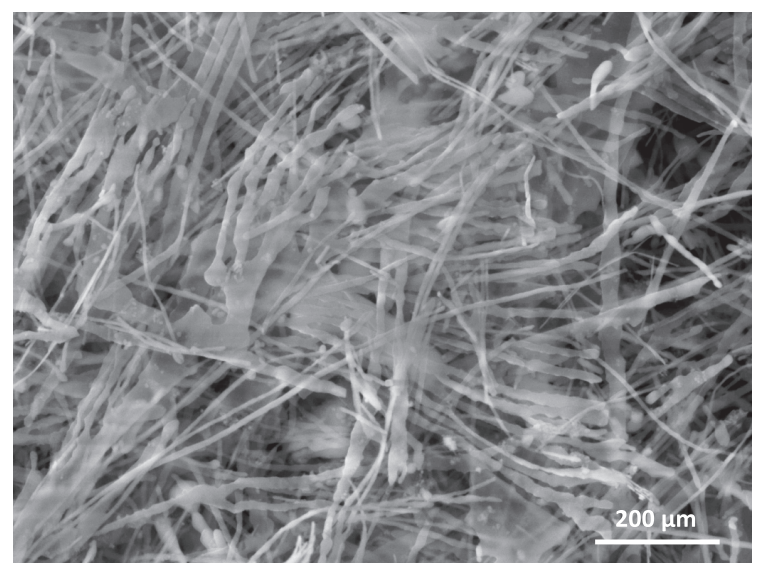

Fig. 4 Micrograph of precipitates separated from $\mathrm{Cu}-4.3$ at $\%$ Ni-2.2 at $\%$ $\mathrm{Si}$ alloy specimen aged at $723 \mathrm{~K}$ for $408 \mathrm{~h}$ using an extraction procedure.

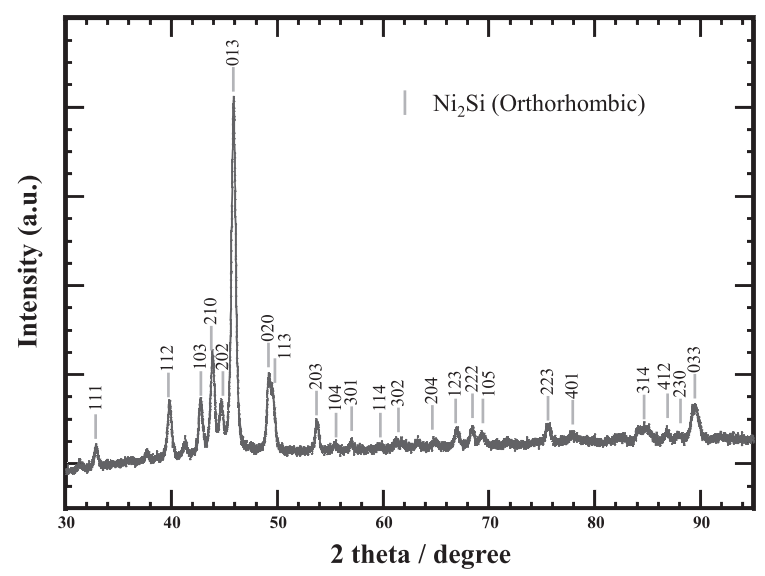

Fig. 5 X-ray diffraction profile of the precipitates separated from $\mathrm{Cu}$ 4.3 at\% Ni-2.2 at\% Si alloy specimen aged at $723 \mathrm{~K}$ for $408 \mathrm{~h}$ using an extraction procedure. filtrate and insoluble residue remaining after the extraction procedure. Table 1 lists the weight fractions of the elements $\mathrm{Cu}, \mathrm{Ni}$, and $\mathrm{Si}$ in the matrix and the precipitates of the specimens aged up to the final state at $698 \mathrm{~K}$ for $530 \mathrm{~h}, 723 \mathrm{~K}$ for $408 \mathrm{~h}, 773 \mathrm{~K}$ for $400 \mathrm{~h}$, and $873 \mathrm{~K}$ for $240 \mathrm{~h}$, which are denoted as $W^{\mathrm{m}}{ }_{\mathrm{Cu}}, W^{\mathrm{m}}{ }_{\mathrm{Ni}}$, and $W^{\mathrm{m}}{ }_{\mathrm{Si}}$, and $W^{\mathrm{p}} \mathrm{Cu}, W^{\mathrm{p}}{ }_{\mathrm{Ni}}$, and $W^{\mathrm{p}}{ }_{\mathrm{Si}}$, respectively. The total weight fractions of the $\mathrm{Cu}, \mathrm{Ni}$, and $\mathrm{Si}$ in the matrix and precipitates of the aged specimens, i.e., $W^{\mathrm{m}}{ }_{\mathrm{Cu}}+W^{\mathrm{m}}{ }_{\mathrm{Ni}}+W^{\mathrm{m}}{ }_{\mathrm{Si}}+W^{\mathrm{p}} \mathrm{Cu}+W^{\mathrm{p}}{ }_{\mathrm{Ni}}+W^{\mathrm{m}}{ }_{\mathrm{Si}}$, were always very close to $100 \%(100 \pm 0.5 \%)$ for all the specimens, suggesting that the chemical extraction procedure could account for all the constituent elements in the specimens.

The validity of the chemical compositions obtained by an extraction procedure and then ICP-OES measurement is also supported by the saturated electrical conductivity measured for the fully aged alloys. The electrical conductivity of the aged alloys can be estimated from the amount of solutes of $\mathrm{Ni}$ and $\mathrm{Si}$ in the matrix, ignoring the contribution of the $\delta-\mathrm{Ni}_{2} \mathrm{Si}$ precipitate phase. Actually, the volume fractions of the $\delta-\mathrm{Ni}_{2} \mathrm{Si}$ precipitates for the specimens that are fully aged at every temperature were estimated to be only less than 5.1 vol\%, using the weight fraction in Table 1 and a calculated density, $7.30 \mathrm{~g} / \mathrm{cm}^{3}$ for $\delta-\mathrm{Ni}_{2} \mathrm{Si}$ and $8.94 \mathrm{~g} / \mathrm{cm}^{3}$ for $\mathrm{Cu}$. The electrical conductivity of the $\mathrm{Cu}$ matrix containing $\mathrm{Ni}$ and $\mathrm{Si}$ solutes, $\sigma$, was estimated using the following Nordheim's equation:

$$
1 / \sigma=1 / \sigma_{\mathrm{Cu}}+A_{\mathrm{Ni}} C_{\mathrm{Ni}}+A_{\mathrm{Si}} C_{\mathrm{Si}}
$$

Here, $\sigma_{\mathrm{Cu}}$ is the electrical conductivity of pure copper, $A_{\mathrm{Ni}}$ and $A_{\mathrm{Si}}$ are the coefficients, and $C_{\mathrm{Ni}}$ and $C_{\mathrm{Si}}$ are the concentrations of solutes $\mathrm{Ni}$ and $\mathrm{Si}$, respectively. The values of $A_{\mathrm{Ni}}$ and $A_{\mathrm{Si}}$ were reported to be $1.25 \times 10^{-8} \Omega \mathrm{m} /$ at $\%$ and $3.95 \times$ $10^{-8} \Omega \mathrm{m} /$ at $\%$, respectively ${ }^{26}$. Thus, the electrical conductivity calculated using eq. (3) was 52\% IACS for the specimen aged at $698 \mathrm{~K}$ for $530 \mathrm{~h}, 51 \%$ IACS for that aged at $723 \mathrm{~K}$ for $408 \mathrm{~h}, 46 \%$ IACS for that aged at $773 \mathrm{~K}$ for $400 \mathrm{~h}$, and $39 \%$ IACS for that aged at $873 \mathrm{~K}$ for $240 \mathrm{~h}$. These values are very close to the measured ones shown in Fig. 2; i.e., $51.4 \%$ IACS at $698 \mathrm{~K}, 50.8 \%$ IACS at $723 \mathrm{~K}, 46.7 \%$ IACS at $773 \mathrm{~K}$, and $38.6 \%$ IACS at $873 \mathrm{~K}$.

Table 1 states that the amount of solute elements of $\mathrm{Ni}$ and $\mathrm{Si}$ in the matrix of the quenched specimen decreased significantly as a result of aging at every temperature, which is due to the formation of $\mathrm{Ni}$ - and $\mathrm{Si}$-enriched precipitates during aging. For the specimens in an equilibrium state, the $\mathrm{Ni}$ and $\mathrm{Si}$ contents in the matrix phase increased slightly with an increase in the temperature. Meanwhile, the precipitates of $\delta-\mathrm{Ni}_{2} \mathrm{Si}$ were found to contain a small amount of $\mathrm{Cu}$, and the $\mathrm{Cu}$ content increased with the temperature. The measured atomic ratio of $\mathrm{Ni} / \mathrm{Si}$ was almost constant, being $1.79 \pm 0.04$, which is somewhat less than the stoichiometric composition of 2.0. This suggests that the $\delta-\mathrm{Ni}_{2} \mathrm{Si}$ intermetallic phase has some compositional range caused by containing $\mathrm{Cu}$ element, which was reported previously ${ }^{27)}$.

The atomic fractions of $\mathrm{Ni}$ and $\mathrm{Si}$ in the matrix, and $\mathrm{Cu}$ in the precipitates of the specimens in the equilibrium state, which were converted from the data in Table 1 and denoted as $C^{\mathrm{m}}{ }_{\mathrm{Ni}}, C^{\mathrm{m}}{ }_{\mathrm{Si}}$, and $C^{\mathrm{p}} \mathrm{Cu}$ [at\%], can be fitted with linear functions and plotted as shown in Fig. 6, and be expressed by the following equations: 
Table 1 Elemental contents in $\mathrm{Cu}$ solid solution and $\delta-\mathrm{Ni}_{2} \mathrm{Si}$ precipitates, and atomic ratio of $\mathrm{Ni} / \mathrm{Si}$ in precipitates for fully aged $\mathrm{Cu}-4.3$ at $\% \mathrm{Ni}-2.2$ at $\% \mathrm{Si}$ alloy specimens, as obtained by extraction procedure and ICP-OES measurement.

\begin{tabular}{|c|c|c|c|c|c|c|c|}
\hline \multirow{2}{*}{ Aging Temp., time } & \multicolumn{3}{|c|}{ Matrix } & \multicolumn{4}{|c|}{ Precipitates } \\
\hline & $W^{\mathrm{m}}{ }_{\mathrm{Cu}}(\mathrm{mass} \%)$ & $\left.W^{\mathrm{m}} \mathrm{Ni}_{(\mathrm{mass}} \%\right)$ & $\left.W^{\mathrm{m}} \mathrm{Si}_{(\mathrm{mass}} \%\right)$ & $W^{\mathrm{P}}{ }_{\mathrm{Cu}}(\operatorname{mass} \%)$ & $W^{\mathrm{P}}{ }_{\mathrm{Ni}}(\operatorname{mass} \%)$ & $W^{\mathrm{P}}{ }_{\mathrm{Si}}(\operatorname{mass} \%)$ & Atomic ratio of $\mathrm{Ni} / \mathrm{Si}$ \\
\hline $698 \mathrm{~K}, 530 \mathrm{~h}$ & $94.93 \pm 0.15$ & $0.604 \pm 0.009$ & $0.073 \pm 0.021$ & $0.048 \pm 0.001$ & $3.363 \pm 0.026$ & $0.898 \pm 0.010$ & $1.79 \pm 0.03$ \\
\hline $723 \mathrm{~K}, 408 \mathrm{~h}$ & $94.96 \pm 0.11$ & $0.609 \pm 0.010$ & $0.080 \pm 0.013$ & $0.045 \pm 0.001$ & $3.361 \pm 0.006$ & $0.924 \pm 0.010$ & $1.74 \pm 0.02$ \\
\hline $773 \mathrm{~K}, 400 \mathrm{~h}$ & $94.67 \pm 0.55$ & $0.644 \pm 0.007$ & $0.117 \pm 0.014$ & $0.053 \pm 0.001$ & $3.439 \pm 0.015$ & $0.897 \pm 0.009$ & $1.81 \pm 0.02$ \\
\hline $873 \mathrm{~K}, 240 \mathrm{~h}$ & $94.85 \pm 0.67$ & $0.712 \pm 0.011$ & $0.178 \pm 0.011$ & $0.095 \pm 0.001$ & $3.231 \pm 0.014$ & $0.851 \pm 0.009$ & $1.82 \pm 0.02$ \\
\hline quenched (before aging) & $94.91 \pm 0.13$ & $3.991 \pm 0.050$ & $1.004 \pm 0.048$ & --- & --- & --- & --- \\
\hline
\end{tabular}

Temperature, $\mathbf{K}$

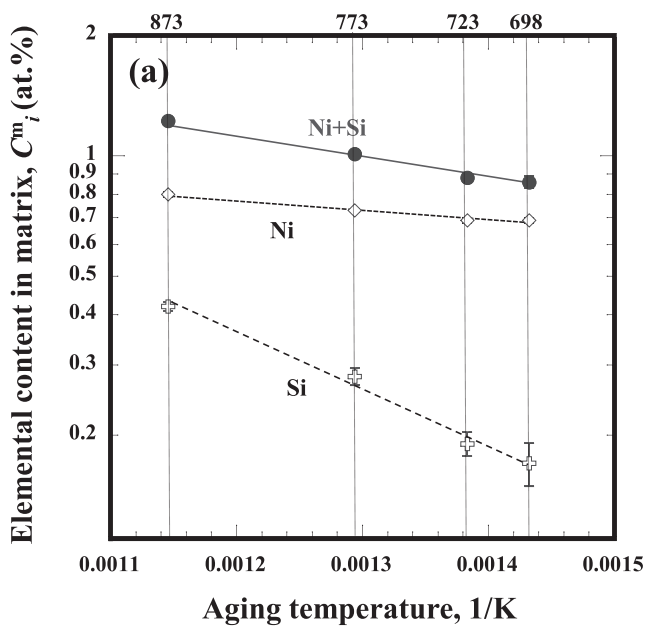

Temperature, $\mathrm{K}$

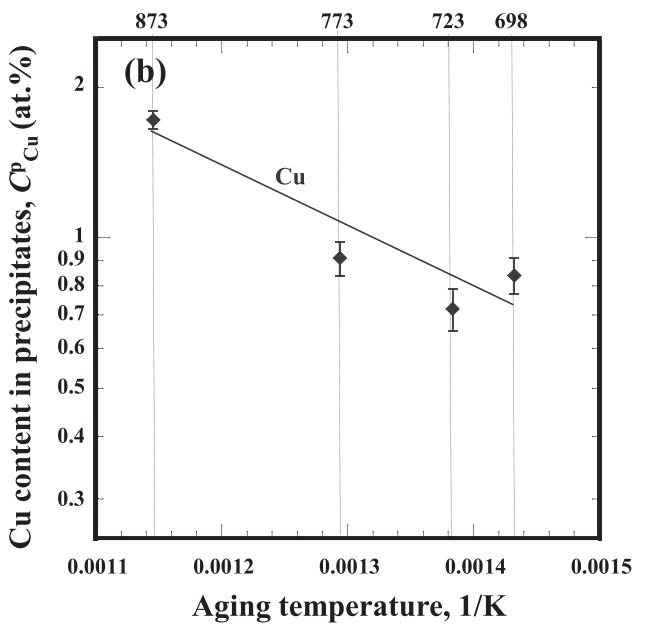

Fig. 6 (a) $\mathrm{Ni}, \mathrm{Si}$, and $\mathrm{Ni}+\mathrm{Si}$ contents in the $\mathrm{Cu}$ solid solution phase and (b) $\mathrm{Cu}$ content in the $\delta$-Ni ${ }_{2} \mathrm{Si}$ precipitate phase of the fully aged $\mathrm{Cu}-4.3$ at $\%$ Ni2.2 at\% Si alloy specimens.

$$
\begin{aligned}
& \ln C^{\mathrm{m}}{ }_{\mathrm{Ni}}=0.397-545.8 / \mathrm{T} \\
& \ln C^{\mathrm{m}}{ }_{\mathrm{Si}}=2.864-3240 / \mathrm{T} \\
& \ln C^{\mathrm{p}}{ }_{\mathrm{Cu}}=3.648-2787 / \mathrm{T}
\end{aligned}
$$

In addition, the solubility product of $\delta-\mathrm{Ni}_{2} \mathrm{Si}$ precipitates in the $\mathrm{Cu}$ solid-solution matrix, $\left(C^{\mathrm{m}} \mathrm{Ni}\right)^{1.79}\left(C_{\mathrm{Si}}^{\mathrm{m}}\right)$, was given from the eqs. (4) and (5), as following,

$$
\ln \left(C^{\mathrm{m}}{ }_{\mathrm{Ni}}\right)^{1.79}\left(C^{\mathrm{m}}{ }_{\mathrm{Si}}\right)=3.579-4222 / \mathrm{T}
$$

Here the power of 1.79 for $C^{\mathrm{m}}{ }_{\mathrm{Ni}}$ is from the $\mathrm{Ni} / \mathrm{Si}$ ratio for $\delta-\mathrm{Ni}_{2} \mathrm{Si}$ precipitates based on the result listed in Table 1 . The $(\mathrm{Ni}+\mathrm{Si})$ content plotted in Fig. 6(a) is fitted by the eq. (7).

The magnitudes of $\left(C^{\mathrm{m}} \mathrm{Ni}\right)^{2}\left(C_{\mathrm{Si}}^{\mathrm{m}}\right)$ and $C^{\mathrm{p}} \mathrm{Cu}$ correspond to the terminal compositions of the matrix and $\delta-\mathrm{Ni}_{2} \mathrm{Si}$ precipitates phases, respectively. Considering the $\mathrm{Cu}-\delta-\mathrm{Ni}_{2} \mathrm{Si}$ pseudo binary system, we can propose the solvus (solid lines) depicted in the phase diagram of Fig. 7, which was constructed using the phase diagram produced by Sokolovslaya et al. from the experimental assessment (dotted lines $)^{28)}$. The terminal composition of the $\delta-\mathrm{Ni}_{2} \mathrm{Si}$ phase defined by eq. (7) is in good agreement with that reported by Sokolovslaya et al. ${ }^{28)}$ with an experimental accuracy, as shown in Fig. 7. Meanwhile, the terminal composition of $\mathrm{Cu}$ solid solution phase, defined by eq. (6) was slightly shifted to the left with respect to the magnitude depicted in the reported diagram.

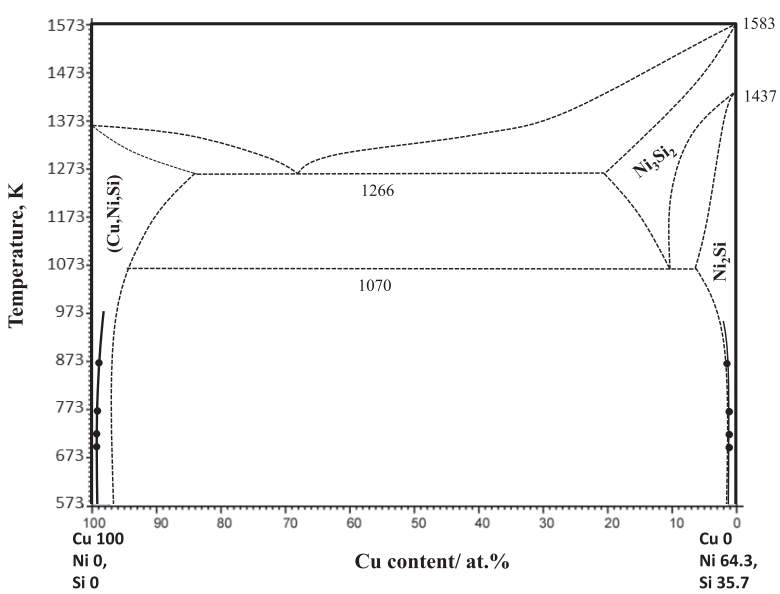

Fig. 7 Solvus obtained in this study (indicated by the solid line), as drawn in the $\mathrm{Cu}-\delta-\mathrm{Ni}_{2} \mathrm{Si}$ pseudo binary phase diagram ${ }^{28)}$. The composition of $\delta-\mathrm{Ni}_{2} \mathrm{Si}$, which is located at the right-hand end of the phase diagram, was assumed to be $\mathrm{Ni}-35.7$ at $\% \mathrm{Si}$ (i.e., $\mathrm{Ni} / \mathrm{Si}=1.79$ ) based on the result listed in Table 1.

Strictly describing, it is controversial whether the content in the matrix and $\delta-\mathrm{Ni}_{2} \mathrm{Si}$ precipitates phases, shown in Fig. 6, corresponds to a true equilibrium composition. The composition measured in this study might be shifted from the true one, arising from contribution of interface energy between the matrix and disk-shaped CPs or fiber-shaped 
DPs with a small diameter of several ten nano-meters, according to Gibbs-Thomson effect ${ }^{29}$. Thus, an influence of precipitation size on the compositional distribution of the constituent phases should be understood to discuss true phase equilibrium. In addition, it should be also important to confirm the solvus at a higher temperature than $873 \mathrm{~K}$, as well as the eutectic and eutectoid points shown in Fig. 7. These can be examined reliably using extraction procedure, which will be reported in a future.

\section{Conclusions}

The precipitation behavior and phase equilibrium for $\mathrm{Cu}-$ 4.1 at $\% \mathrm{Ni}-2.2$ at $\% \mathrm{Si}$ alloy isothermally aged at temperatures of $698 \mathrm{~K}-873 \mathrm{~K}$ were investigated in the present study. On the basis of the results obtained, the kinetics of the microstructural subsequence and the saturated composition of the constituent phases were quantitatively evaluated. The salient findings can be summarized as follows:

(1) The microstructural subsequence of those specimens aged at a temperature of $698 \mathrm{~K}-873 \mathrm{~K}$ progressed in accordance with the following subsequence; continuous precipitation of fine disk-shaped $\delta$ - $\mathrm{Ni}_{2} \mathrm{Si}$ particles, discontinuous precipitation of cellular components containing coarse fiber-shaped $\delta-\mathrm{Ni}_{2} \mathrm{Si}$, and eventual occupation of the specimen with cellular components. Accordingly, the quenched specimen aged at these temperatures is finally decomposed into a two-phase microstructure consisting of a $\mathrm{Cu}$ solid solution and $\delta-\mathrm{Ni}_{2} \mathrm{Si}$ precipitates.

(2) The kinetics of the maximum-hardness can be approximated by eq. (1), which must correspond to the highest number density of continuous precipitates of fine $\delta-\mathrm{Ni}_{2} \mathrm{Si}$ hardening species. The kinetics of the saturated electrical conductivity are described by eq. (2), which corresponds to the phase equilibrium.

(3) The $\delta-\mathrm{Ni}_{2} \mathrm{Si}$ precipitates in the fully aged specimens contain a small amount of $\mathrm{Cu}$, the content of which increases slightly with the aging temperature. The solvus of the $\mathrm{Cu}$ for the $\delta-\mathrm{Ni}_{2} \mathrm{Si}$ phase can be provided by eq. (6). The measured $\mathrm{Ni} / \mathrm{Si}$ ratio was $1.79 \pm 0.04$ which is somewhat less than the stoichiometric composition of 2.0. The amount of $\mathrm{Ni}$ and $\mathrm{Si}$ elements in the $\mathrm{Cu}$ solid solution also increases with the aging temperature, as defined by eq. (7). The solvus revised in this study slightly shifted to the $\mathrm{Cu}$-rich side in comparison with the $\mathrm{Cu}-\delta-\mathrm{Ni}_{2} \mathrm{Si}$ pseudo-binary diagram produced by Sokolovslaya et al.

\section{Acknowledgements}

The original alloy ingot was provided by YAMATO ALLOY Co., Ltd. The authors are grateful to Prof. S. Hanada, and Prof. N. Masahashi of the Institute for Materials Research (IMR) of Tohoku University, Dr. A. Sugawara and Mr. H. Suda of DOWA METALTECH Co.,
Ltd. for their useful discussions and comments. The authors also thank Mr. E. Aoyagi of the IMR for the technical assistance that was provided. Financial support provided by the Japan Society for the Promotion of Science (JSPS) as a Grant-in-Aid for Scientific Research (C) (No. 26420663) and by the Japan Copper and Brass Association are gratefully acknowledged.

\section{REFERENCES}

1) H. Tsubakino, R. Nozato and A. Yamamoto: J. Mater. Sci. 26 (1991) 2851-2856.

2) C. Watanabe, T. Sakai and R. Monzen: Philos. Mag. 88 (2008) 1401-1410.

3) M.G. Corson: Iron. Age (Omaha) 119 (1927) 421-424.

4) M.G. Corson: Electr. World (Brisb.) 89 (1927) 137-139.

5) Z. Rdzawski and J. Stobrawa: Mater. Sci. Technol. 9 (1993) 142-149.

6) F. Huang, J. Ma, H.L. Ning, Y.W. Cao and Z. Geng: Mater. Lett. 57 (2003) 2135-2139.

7) R. Monzen and C. Watanabe: Mater. Sci. Eng. A, 483-483 (2014) 117-119.

8) S. Lee, H. Matsunaga, X. Sauvage and Z. Horita: Mater. Charact. 90 (2014) 62-70.

9) M. Gholami, J. Vesely, I. Altenberger, H.-A. Kuhn, M. Janecek, M. Wollmann and L. Wagner: J. Alloy. Compd. 696 (2017) 201-212.

10) S.A. Lockyer and F.W. Noble: J. Mater. Sci. 29 (1994) 218-226.

11) D.M. Zhao, Q.M. Dong, P. Liu, B.X. Kang, J.L. Huang and Z.H. Jin: Mater. Sci. Eng. A 361 (2003) 93-99.

12) Y. Takahashi, T. Sanada, S. Sato, T. Okajima, K. Shinoda and S. Suzuki: Mater. Trans. 48 (2007) 101-104.

13) E. Donoso, R. Espinoza, M.J. Dianez and J.M. Criado: Mater. Sci. Eng. A 556 (2012) 612-616.

14) J. Yan-lin, W. Ming-pu, C. Chang, D. Qi-yi, W. Shan and L. Zhou: J. Alloy. Compd. 557 (2013) 147-51.

15) T. Hu, J.H. Chen, J.Z. Liu, Z.R. Liu and C.L. Wu: Acta Mater. 61 (2013) 1210-1219.

16) H. Azzeddine, B. Mehdi, L. Hennet, D. Thiaudière, B. Alili, M. Kawasaki, D. Bradai and T.G. Langdon: Mater. Sci. Eng. A 597 (2014) 288-294.

17) S. Semboshi, S. Sato, A. Iwase and T. Takasugi: Mater. Charact. 115 (2016) 39-45.

18) F. Bosselet, J.C. Viala, C. Colon, B.F. Mentzen and J. Bouix: Mater. Sci. Eng. A 167 (1993) 147-154.

19) Q. Lei, Z. Li, M.P. Wang, L. Zhang, S. Gong, Z. Xiao and Z.Y. Pan: J. Alloy. Compd. 509 (2011) 3617-22.

20) E. Lee, K.K. Euh, S.Z. Han, S.H. Lim, J.H. Lee and S.S. Kim: Met. Mater. Int. 19 (2013) 1183-1188.

21) C. Watanabe, R. Monzen and K. Higashimine: Proceedings of an International Conference on Solid-Solid Phase Transformations in Inorganic Materials, 1 (2005) 713-718.

22) S. Semboshi, M. Ishikuro, S. Sato, K. Wagatsuma and T. Takasugi: Mater. Charact. 82 (2013) 23-31.

23) S. Semboshi, S. Amano, J. Fu, A. Iwase and T. Takasugi: Metall. Mater. Trans., A 48 (2017) 1501-1511.

24) R. Landauer: J. Appl. Phys. 23 (1952) 779-874.

25) J. Miyake and M.E. Fine: Acta Metall. Mater. 40 (1992) 733-741.

26) J.S. Smart, A.A. Smith, Jr. and J.A. Philips: Trans. Metall. AIME 143 (1941) 272.

27) W. Sun, H. Xu, S. Liu, Y. Du, Z. Yuan and B. Huang: J. Alloy. Compd. 509 (2011) 9776-9781.

28) E.M. Sokolovslaya, O.I. Chechernikova, E.I. Gladyshevskii and O.I. Bodak: Russ. Metall. 6 (1973) 114-118.

29) M. Perez: Scr. Mater. 52 (2005) 709-712. 